\title{
THE TRANSACTIONAL ASSET PRICING APPROACH(TAPA): INCORPORATION OF LEVERAGE AND DERIVATION OF EXTENDED ELLWOOD FORMULA WITH FIXED LEVERAGE BENEFITS
}

\author{
Vladimir B. Michaletz \\ RF Directorate of State Scientific Research Programs, Russia \\ e-mail:mihail-mmm@mail.ru \\ Andrey I. Artemenkov \\ The Westminster International University in Tashkent, WIUT, Uzbekistan \\ e-mail:achudakhin02@gmail.com, aartemenkov@wiut.uz
}

\begin{abstract}
The Paper discusses the derivation of the Ellwood formula on the basis of the Transactional Asset Pricing approach to valuation (TAPA) and proceeding from the dynamic principle of transactional equity-in-exchange.

Discussing the notion of leverage, it introduces a formulation, in capitalized value terms, and measurement, for leverage benefits to a property purchaser. It is found that such a measure for the Ellwood formula is always zero, essentially obviating any-gains-from-trade to the purchasers of property to be had on account of leveraged transactions. To address this weakness in the Ellwood formula, a modified formula is proposed, which accounts for the requirement of positivity of leverage benefits to the purchaser of property.
\end{abstract}

Key words: Ellwood formula, Transactional Asset pricing Approach (TAPA), leverage benefits, property valuation, the principle of transactional equity-in exchange.

JEL Classification: D46, G12.

Citation: Michaletz, V.B. \& Artemenkov, A. I. (2021). The transactional asset pricing approach (TAPA): incorporation of leverage and derivation of extended Ellwood formula with fixed leverage benefits. Real Estate Management and Valuation, 29(1), 54-71.

DOI: https://doi.org/10.2478/remav-2021-0006

\section{Introduction}

The income approach to the valuation of assets, despite its weight of history and a seemingly settled nature in the context of financial economics and property valuation, is still able to offer novel insights about its nature and analytical genesis. In particular, a transactional- based justification and analytical basis for this approach resulting from the decision theory was offered in recent publications such as Galasyuk (2018), as well as under the Transactional Asset Pricing Approach (TAPA) (Michaletz \& Artemenkov, 2018). The Paper continues developing the TAPA approach to enable the incorporation of leverage effects into the TAPA framework.

\section{Literature review}

Reviews of the latest income approach and conceptual valuation literature Mooya (2016), Jefferies (2017), Sanders (2018) and Kucharska-Stasiak (2019) have identified a number of important trends in 
the continuing evolution of the income approach to property valuation. In particular, explicit incorporation of the cyclical nature of the real estate market into property valuation models is deemed to be a hot-button issue (Kucharska-Stasiak, 2019; d'Amato, et al. 2019). The authors hereof had outlined a general-purpose Transactional Asset pricing approach (TAPA), which allows for the cyclical nature of the real estate markets to be explicitly accounted for via the use of time-variable discount rates in the DCF valuation process, in a number of their preceding publications including with REMV and JPIF (Michaletz, et al., 2007; Michaletz \& Artemenkov, 2018; Michaletz \&Artemenkov, 2019). It turned out that TAPA offers a more general formulation for the meta-DCF analysis based on the proposed principle of inter-temporal transactional equity, of which the conventional (singlediscount-rate) DCF approach (and related income capitalization models) appear as specific-case reductions. However, the TAPA approach to date lacked any refinements associated with the incorporation of debt finance (leverage), where it becomes a factor in property market pricing. The authors have decided to address this methodological hiatus within TAPA and obtain a version of TAPA DCF analysis with leverage. As shown in this Paper, a novel generalized version of the Ellwood formula with fixed leverage benefits is derivable under TAPA's methodological assumptions (proceeding from the principle of inter-temporal transactional equity-in-exchange), of which the conventional Ellwood formula appears as a specific case reduction, the same way as the conventional single-discount-rate DCF analysis appears as a specific case of more general dual-rate asset pricing formulas formulated in Michaletz and Artemenkov (2019).

The Ellwood approach to property pricing is presently oftentimes more honored by oblivion than its use. Yet it is not infrequently taught at the advanced level of appraisal courses, despite its putative "historicity"-- since it aims to consider the feedback between the effects caused by funding leverage and the property market value. Its critique usually focuses on the flaws dealing with the assumed constancy of property income (a fact implied by the unadjusted Ellwood formula setting discussed in this Paper (i.e. one without J- and K-factor loads) (Kelly, et al., 1995). What is often overlooked in such a critique is a patent distributional non-neutrality of the Elwood approach, i.e. the splitting of leverage benefits from a projected property transaction in favor of the seller. We address this somewhat overlooked matter explicitly in the Paper, and rather than suggesting to discard the Ellwood approach to property pricing outright, as in Kelly et al., 1995), offer a way to ameliorate this distributional skewedness of the Ellwood method by introducing the fixed leverage adjustment to the Elwood formula. The Ellwood approach is also subjected to criticism (e.g. in Kelly et al., 1995) for the assumption of circularity between the present and future values of the property. From the TAPA point of view, as this Paper explains, this can hardly be a locus of criticism, since the Elwood use of this feature had, by almost half a century, foreshadowed the similar element in TAPA.

\section{Data and Methods}

This is an analytical Paper. Therefore, it uses computer-generated evaluations for a property valuation example performed in Mathcad to illustrate and verify analytical derivations of the formulas.

\subsection{Starting point: Formulating TAPA's DCF for the case without leverage: TAPA's principle of transactional equity-in-exchange}

A distinguishing feature of the Transactional Asset Pricing Approach (Michaletz \& Artemenkov, 2019) is in that it recasts the basic derivations of Valuation theory models under the income approach, proceeding from an explicit transaction-based perspective (i.e. the interests of both transacting parties - buyer's and seller's-explicitly feature in the modelling formulations, as opposed to the conventional specific investor-based standpoint/orientation, on which the DCF is conceptualized, found in such classical works as Fisher (1930) or reference sources, such as Friedman and Ordway (1989), or a competitive-market orientation found in Miller and Modigliani (1961). In lieu of implications from a singular specific-investor basis, a holistic transactional view (involving both transacting agents) is substituted.

The point of departure for TAPA's transactional view is the following model situation. Assume that an agent owns an asset, which annually yields the net operating income $E_{i}$. (i $=1 \ldots \mathrm{n}$ periods/years). Should the agent be inclined to dispose of the asset, the agent's natural wish is not to be the losing party in the transaction. This means that they will sell their asset on condition that the consideration they receive in the transaction is capable of generating the same amount of capital in the future as the combined option of (1) keeping the asset to themselves and thus earning a future stream of $E_{i}$ and (2) 
having the right to sell the asset at a reversionary value sometime in the future (in the year $n$ ) over its economic life (i.e. the principle of dynamic equivalence of interests or "the principle of transactional equity-in-exchange").

Thus, both potentially transacting agents - the seller and the buyer -- will regard the following dynamic "transactional equilibrium" condition as equitable (see Fig 1):

$$
S_{n}^{s}=S_{n}^{b}
$$

where:

$S_{n}^{S}$ - is the amount of capital in an "investment opportunity set" available to the selling agent ("seller") in Year $n$ after the deposition into it ${ }^{1}$ of the proceeds $P V$ from the assets' disposal at time 0 ; and

$S_{n}^{b}$ - stands for the amount of capital in Year $n$ accumulated by the counterparty (buyer) as a result of the ownership interest in the purchased asset (the sum of their future Ei-s up until Year $n$ which they reinvest with reference to their "investment opportunity set" plus the residual value of the asset in the Year $n$ which can be converted into cash).

If the considered transaction takes place, the prudent seller will invest their transaction proceeds $V$ according to opportunities offered by the "investment sets" / benchmarks of their choice, where the proceeds will start accumulating due to reinvestments of the accrued annual interest (yield) up until Year $n$ :

$$
S_{n}^{s}=V \prod_{p=1}^{n}\left(1+i^{s}(p)\right)
$$

where:

$i^{s}(p)$ - is the annual rate of return for period (year) $p,(0<p \leq n)$ arising from the seller's "investment opportunity set".

The prudent buyer is able to obtain similar investment advantages by investing into their own "investment opportunity sets" their annual operating income $E_{i}(1<i \leq n)$ arising from the purchased subject asset, so that their initial transaction-related capital $S_{n}{ }^{b}$ by the end of Year $n$, along with the Residual (reversionary) value of the asset now in their possession $S_{\text {res }}$, equals:

$$
\begin{aligned}
& =E_{1} \cdot\left(1+i^{b}(2)\right) \cdot\left(1+i^{b}(3)\right) \cdot \ldots \cdot\left(1+i^{b}(n)\right)+ \\
& +E_{2} \cdot\left(1+i^{b}(3)\right) \cdot\left(1+i^{b}(4)\right) \cdot \ldots \cdot\left(1+i^{b}(n)\right)+\ldots \\
S_{n=}^{b} \sum_{k=1}^{n} E_{k} \prod_{p=k+1}^{n}\left(1+i^{b}(p)\right)+S_{r e s}= & +E_{p} \cdot\left(1+i^{b}(p+1)\right) \cdot\left(1+i^{b}(p+2)\right) \cdot \ldots \cdot\left(1+p^{b}(n)\right)+\ldots+E_{n}+S_{r e s}
\end{aligned}
$$

where $i^{b}(p)$ is the rate of return applicable to the buyer's benchmark investments in period $p$ within the projection/ forecast period $(p=1 . . n)$.

By combining expressions (1), (2) and (3), we can derive, through the "transaction based perspective", a value-in-exchange for the asset, which would be "fair"/"equitable" (in IVSs 2020 sense) from both the buyer's and the seller's standpoints:

$$
V=\frac{\sum_{k=1}^{n-1} E_{k} \prod_{p=k+1}^{n}\left(1+i^{b}(p)\right)+E_{n}}{\prod_{p=1}^{n}\left(1+i^{s}(p)\right)}+\frac{S_{r e s}}{\prod_{p=1}^{n}\left(1+i^{s}(p)\right)}
$$

\footnotetext{
${ }^{1}$ In line with FISHER (1930), the notion of an "Investment opportunity set" implies an appealingly profitable and equally accessible investment opportunity to both parties of a transaction (a bank deposit, setting up a new business, investing in a securities portfolio, real property, reinvesting back into expansion of the business with the subject asset, etc., or a mixture of all these options, i.e. an investment portfolio).

$2 \prod_{p=1}^{n}\left(1+i^{s}(p)\right)$ means the product (chain multiplication) of the yields for each year from $1^{\text {st }}$ to $n$-th, i.e. the expression (2) can be recast as: $S_{n} s=V\left((1+i(1))^{*}(1+i(2))^{*}(1+i(3)) * \ldots *(1+i(n))\right)$
} 


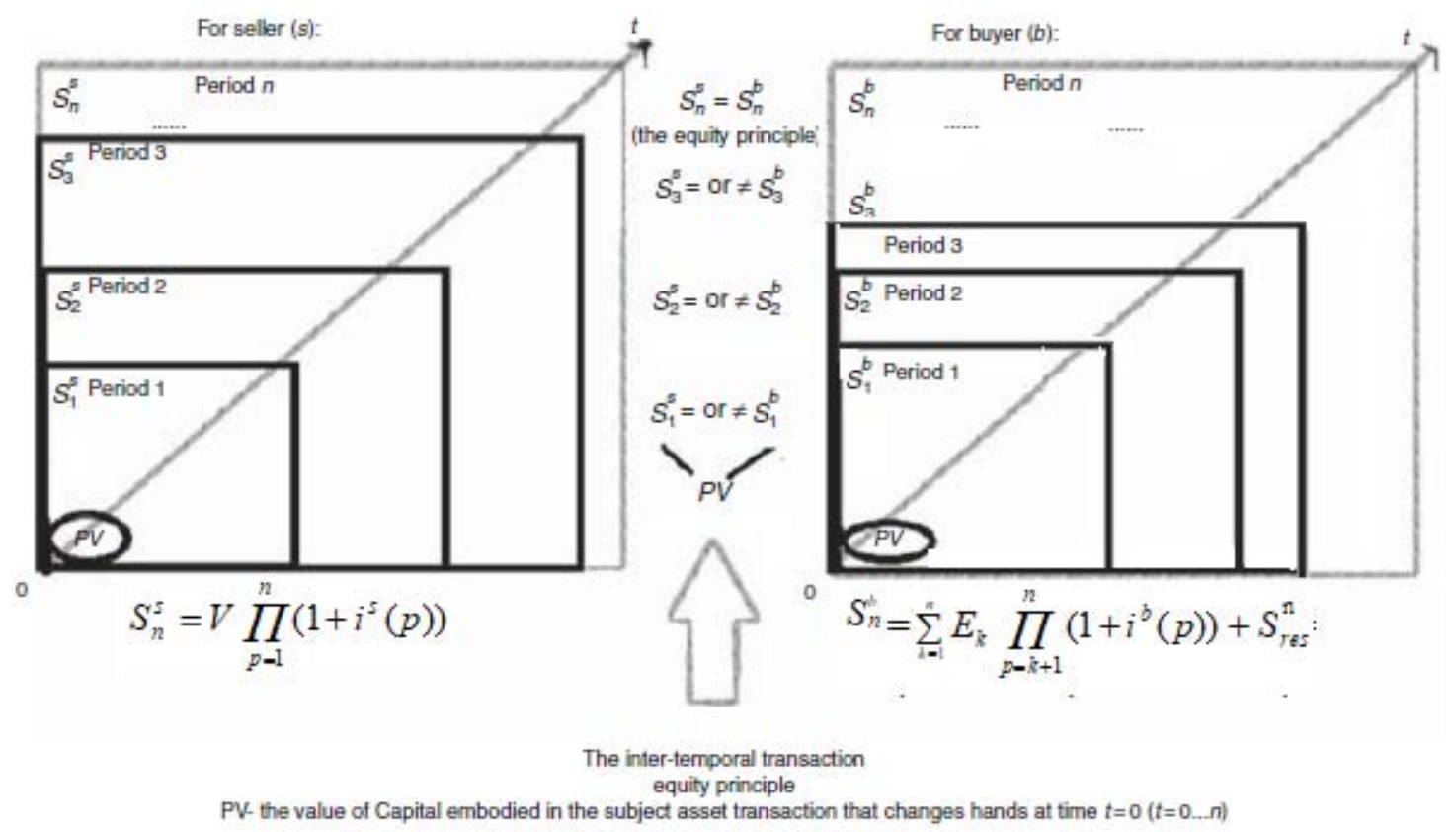

Fig. 1. Multi-period illustration for the intertemporal principle of transactional equity. Source: own study.

Comments on Fig. 1: This is a graphic illustration of the TAPA's dynamic principle of transactional equity-in-exchange. The area of each rectangle represents the accumulation/growth, in value terms and over time, of capital embodied in the asset transaction. The initial transactional capital is represented in the subject asset value, $V$, sought at time 0 . Then it cumulates to $S^{s}{ }_{t}$ and $S^{b}{ }_{t}$ (with $t$-for time subscripts) in the respective investment opportunities ("benchmarks") of the transacting parties: buyer- $b$, seller $-s$. There may be initial disparities in the rate of projected capital accumulation as between the transacting agents (i.e., as a general case and as is depicted in Fig. 1, areas of the inner rectangles won't be equal as between the left-hand (seller) and right-hand (buyer) panels), but the intertemporal principle of transactional equity posits the accumulation of capital embodied in the transaction at $V$ at time 0 as being in equilibrium at the end of the projection/analysis period (i.e. at $k, p=n)$, that is, the outer rectangles on each panel in Fig 1 are assumed to be strictly equal in area.

Implications from such dual-rate meta-DCF pricing Equation (4) have been explored in Michaletz and Artemenkov (2019) for the Fair/Equitable value setting. In Michaletz and Artemenkov (2019) it has been shown that, as the markets form from isolated exchanges and their efficiency improves, buyer's and seller's own discount rates (rates of return) converge to their representative market value $i(p): i^{s}(p)=i^{b}(p)=i(p)$, which, if used in the Equation (4) context, further reduces it to a form of a DCF single-rate-with-time-variation format (Formula 5):

$$
V=\sum_{k=1}^{n} \frac{E_{k}}{\prod_{p=1}^{k}(1+i(p))}+\frac{S_{r e s}}{\prod_{p=1}^{n}(1+i(p))}
$$

This, in turn, implies that the conventional DCF analysis has this strong implicit assumption whenever it is used for Market or Fair/Equitable value valuation situations, namely, that both rates of return are uniform as between the buyers and sellers: $i^{s}(p)=i^{b}(p)=i(p)$. In a simplified case of the discount rate, time-invariance over the forecast period, $i(p)=i$, chain-multipliers in the denominators of Formula (1.5) are further reduced to exponents, which is how the DCF formula is usually presented in a great majority of textbooks on asset pricing, financial economics and property valuation (e.g. Friedman and Ordway (1989)): 


$$
V=\sum_{p=1}^{n} \frac{E_{p}}{(1+i)^{p}}+\frac{S_{r e s}}{(1+i)^{n}}
$$

It is often assumed that the subject property net operating income is invariable over time and, therefore, represents a time-bounded annuity, that is to say, $E_{p}=E$. Having regard to this assumption, and utilizing the elementary formula for the sum of a diminishing geometrical progression, it is further possible to reduce (6) as follows:

$$
V=\frac{E}{i}\left(1-\frac{1}{(1+i)^{n}}\right)+\frac{S_{r e s}}{(1+i)^{n}}
$$

The reversionary value term $S_{\text {res, }}$, can be linked to the present value, $\mathrm{V}$, sought via an imputation of a term for the subject property cumulative rate of change over the forecast period - $u$ (whether positive or negative) as follows:

$$
S_{\text {res }}=P V(1+u)
$$

Then, having regard to the conventional notation for the six functions of money used in valuation ${ }^{3}$, Formula 7 can be rewritten as:

$$
V=E * \frac{F 5(n, i)}{1-(1+u) * F 4(n, i)}
$$

Expression (9) represents the basic pricing formula for property valuation annuities with reversionary interest which has a direct affinity with the TAPA's Basic Pricing Equation derived in Michaletz and Artemenkov (2018), Michaletz and Artemenkov (2019) ${ }^{4}$. We shall proceed to use it as a starting point in the next section to outline the impact of debt financing on the value of subject property.

\section{Example of Formula (9) usage}

Let's introduce an example to be used as an illustration through the rest of the text. Assume a subject property with the net operating income of Eo $:=300000$ currency units under the assumption of no inflation. It is further assumed that the subject property projected holding period (projection/forecast) period is $n b:=10$ years, with the relevant property market rate of return (discount rate) assumed at $i b:=0.14$ per annum for each year within the holding period. A linear market depreciation pattern is assumed for the property over the entirety of the holding period. Thus, the depreciation model includes the cumulative depreciation rate: $\mathrm{u}:=-0.1$ (decline in value of the property by $10 \%$ over the entirety of the holding period) and its residual value by the end of the holding period can be expressed as:

$$
\mathrm{S}_{\mathrm{res}}=\mathrm{V} \times(1+\mathrm{u})
$$

where:

$\mathrm{V}$ - is the present (market) value of subject property (yet unknown).

The present value of subject property, $V$, equitable both for the buyer and seller according to the TAPA's principle of transactional equity-in-exchange, is represented under Formula (9) as follows:

\footnotetext{
${ }^{3} F 1(n, i)=(1+i)^{n}-$ Future value of 1 zloty;

$F 2(n, i)=\left((1+i)^{n}-1\right) / i$ - Future value of 1 zloty per period;

$F 3(n, i)=1 / F 2(n, i)-$ sinking fund factor $(\mathrm{SFF})$;

$F 4(n, i)=1 / F 1(n, i)-$ Present value of 1 zloty;

$F 5(n, i)=\left(1-1 /(1+i)^{n}\right) / i$ - present value of 1 zloty annuity per period;

$F 6(n, i)=1 / F 5(n, i)$ - Periodic payment to amortize 1 zloty
}

This notational shorthand is used further throughout this Paper.

4 The only material difference being that, in the present Paper, the discount rate $i$ is not analyzed via a breakdown into its growth $[u(p), v(p)]$ and yield $[R]$ components for the assumed benchmark of valuation and is assumed here, as is done in conventional DCF analyses, as an aggregate input with time-invariant properties. 


$$
\mathrm{W}:=\mathrm{Eo} \cdot \frac{\mathrm{F} 5(\mathrm{nb}, \mathrm{ib})}{1-(1+\mathrm{u}) \cdot \mathrm{F} 4(\mathrm{nb}, \mathrm{ib})}
$$

where:

Fk (n,i) - is the k-th function of the dollar (see Footnote above for notation),

n - number of periodic payments; i -- rate of return/discount rate for the overall property.

Evaluating the expression $(10 \mathrm{~b})$ using data from the example: $\mathrm{V}=2066523.398 \mathrm{CUs}^{5}$.

It follows from (9) and (10b) that, in the case of the subject property value remaining, as expected, unchanged over the projection period, that is in the case of $\mathrm{u}=0$, the present value of the property would have been:

$$
\begin{aligned}
& \mathrm{Vo}:= \mathrm{Eo} \cdot \frac{\mathrm{F} 5(\mathrm{nb}, \mathrm{ib})}{1-(1+0) \cdot \mathrm{F} 4(\mathrm{nb}, \mathrm{ib})} \\
& \mathrm{Vo}=2142857.14
\end{aligned}
$$

It should be noted, as shown in Michaletz and Artemenkov (2018), that the value of the property in this case could have been determined in an even simpler way, via the direct income capitalization (DIC) format:

$$
\text { Vo }:=\frac{\text { Eo }}{\mathrm{ib}} \rightarrow 2142857.1428571428571
$$

This important condition also derives from the relations between the functions of the dollar, considering that $\mathrm{F} 5(\mathrm{n}, \mathrm{i})=(1-\mathrm{F} 4(\mathrm{n}, \mathrm{i})) / \mathrm{i}$.

Now, let's address the issue of incorporating debt into the pricing equation (9). In order to avoid doubt, we will consider a general scenario in which a change in the prospective value of subject property, $S_{\text {res }} v s V$, can be other than zero $(\mathrm{u}>$ or $<0)$.

\subsection{Valuation of subject property purchased with loanable funds}

\subsubsection{Analysis of leverage benefits accruing to the purchaser of property (investor)}

The value of property is formed under the impact of supply and demand factors. It may seem that the property market value is not contingent upon a property funding decision on the part of a purchaser. However, the balance of appraisal opinion since Ellwood and market analyses testify to the opposite. Let's see why.

Continuing the example which concludes Section 3.1, we shall assume that a property buyer, while purchasing the income-producing property, can borrow a fraction of the property value $M:=0.7$, otherwise known as the LTV (loan-to-value) ratio, from a creditor at the monthly rate of $i k=\frac{0.1}{12}$ (i.e. $10 \%$ per annum $/ 12$ months) for $n k=20 \cdot 12$ months, and such a loan will, consequently, amount to: $\mathrm{M} \times \mathrm{V}=1446566.379$.

Since the buyer will now have to amortize the loan from the proceeds of the property's net operating income, the potential periodic (annual) net income accruing to the buyer will now amount to:

$$
\mathrm{E}:=\mathrm{Eo}-\mathrm{M} \cdot \mathrm{V} \cdot \mathrm{F} 6(\mathrm{nk}, \mathrm{ik}) \cdot 12
$$

Evaluating the expression: $\mathrm{E}=132483.86$. An assumption of loan amortization in equal installments is used at the same time the potential reversionary proceeds from selling the property after $n b$ years accruing to the buyer will be:

$$
\text { Sres }:=\mathrm{V} \cdot(1+\mathrm{u})-\mathrm{M} \cdot \mathrm{V} \cdot \mathrm{F} 5(\mathrm{nk}-\mathrm{nb} \cdot 12, \mathrm{ik}) \cdot \mathrm{F} 6(\mathrm{nk}, \mathrm{ik})
$$

Evaluating, Sres $=803525.934$ (after settling the debt).

This means that the current (present) value of all the benefits accruing to the purchaser over the holding period is:

\footnotetext{
5 Unless explicitly stated otherwise, all evaluations throughout this Paper are carried out in notional Currency Units (CUs)
} 


$$
\begin{aligned}
& W(M, i b, i k, n k, n b):=(E o-M \times V \times F 6(n k, i k) \times 12) \times F 5(n b, i b) \ldots \\
& +[V \times(1+u)-M \times V \times F 5(n k-n b \times 12, i k) \times F 6(n k, i k)] \times F 4(n b, i b)
\end{aligned}
$$

Evaluating, W( M, ib, ik, nk, nb) = 907797.261.

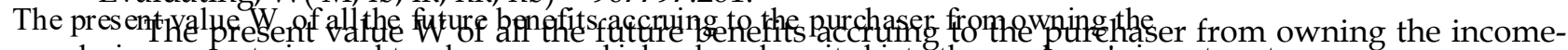
income-producing property is equal to a lump sum which when depesited into the purchaser's investment opportunity set at the rate of return ib for $n b$ years, generates exactly the same income to the purchaser as as the the purchaser the purchased oppoperty

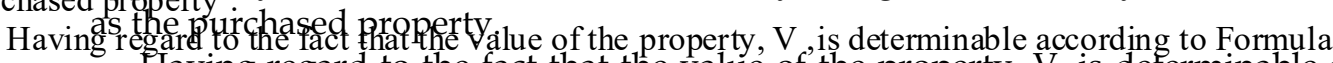

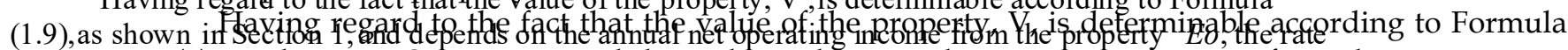

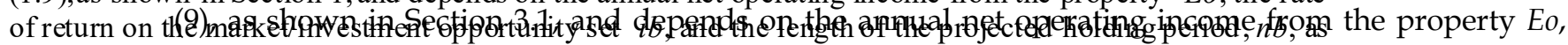

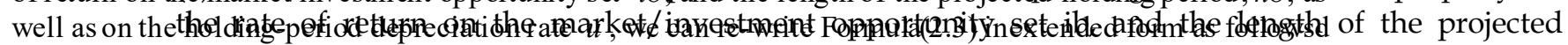
form as followolding period, $\mathrm{nb}$, as well as on the holding-period depreciation rate, $\mathrm{u}$, for the property, we can rewrite Formula (14) in extended form as follow. Remembering that $\mathrm{W}$ depends on:

$$
\begin{aligned}
& \mathrm{V}(\mathrm{Eo}, \mathrm{nb}, \mathrm{ib}, \mathrm{u}):=\mathrm{Eo} \cdot \frac{\mathrm{F} 5(\mathrm{nb}, \mathrm{ib})}{1-(1+\mathrm{u}) \cdot \mathrm{F} 4(\mathrm{nb}, \mathrm{ib})}, \\
& \mathrm{W}(\mathrm{M}, \mathrm{Eo}, \mathrm{ib}, \mathrm{ik}, \mathrm{nk}, \mathrm{nb}, \mathrm{u}):=(\mathrm{Eo}-\mathrm{M} \cdot \mathrm{V}(\mathrm{Eo}, \mathrm{nb}, \mathrm{ib}, \mathrm{u}) \cdot \mathrm{F} 6(\mathrm{nk}, \mathrm{ik}) \cdot 12) \cdot \mathrm{F} 5(\mathrm{nb}, \mathrm{ib}) \ldots \\
& +\left[\begin{array}{l}
\mathrm{V}(\mathrm{Eo}, \mathrm{nb}, \mathrm{ib}, \mathrm{u}) \cdot(1+\mathrm{u}) \ldots \\
+-\mathrm{M} \cdot \mathrm{V}(\mathrm{Eo}, \mathrm{nb}, \mathrm{ib}, \mathrm{u}) \cdot \mathrm{F} 5(\mathrm{nk}-\mathrm{nb} \cdot 12, \mathrm{ik}) \cdot \mathrm{F} 6(\mathrm{nk}, \mathrm{ik})
\end{array}\right] \cdot \mathrm{F} 4(\mathrm{nb}, \mathrm{ib})
\end{aligned}
$$

For the inputs assumed in our example above, the present value of the purchaser's benefits $\mathrm{W}$ is ascertainable as: $\mathrm{W}(\mathrm{M}, \mathrm{Eo}, \mathrm{ib}, \mathrm{ik}, \mathrm{nk}, \mathrm{nb}, \mathrm{u})=907797$.

Let's analyze this formula $\mathrm{W}(\mathrm{M}, \mathrm{Eo}, \mathrm{ib}, \mathrm{ik}, \mathrm{nk}, \mathrm{nb})$ for benefits of a loan-reliant purchaser.

In the case of purchaser's LTV changing in the range of M3 := 0, 0.01.. 1, the present value of purchaser's benefits will depend on influencing factors as shown in Figs. 2 and 3.

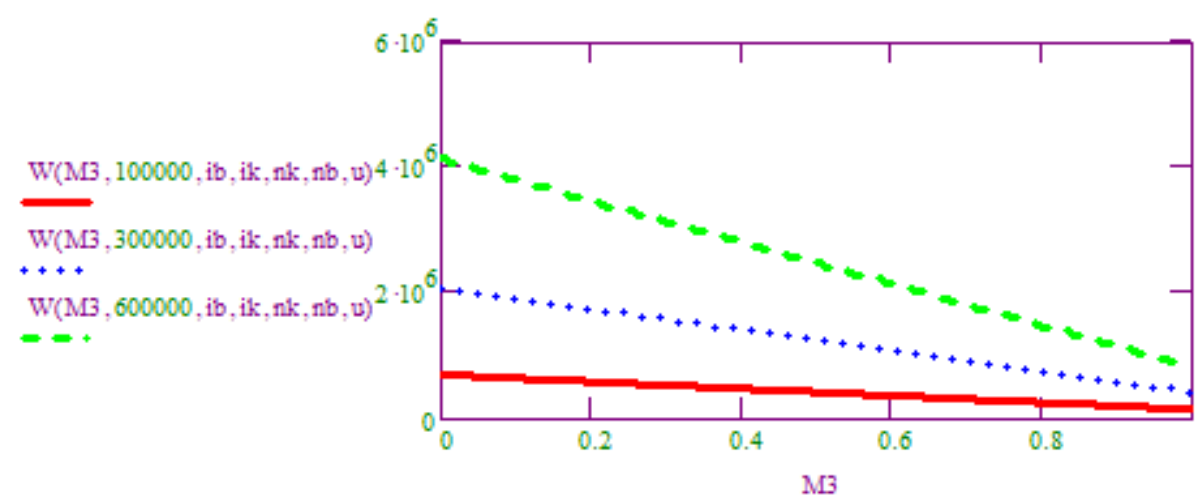

Fig. 2. Dependence of purchaser's benefits, in present-value terms, on the transaction LTV ratio (M3), given property NOIs (Eo) equaling 100000, 300000 and 600000 currency units. (at $\mathrm{ib}=14 \%$ per annum). Source: own study.

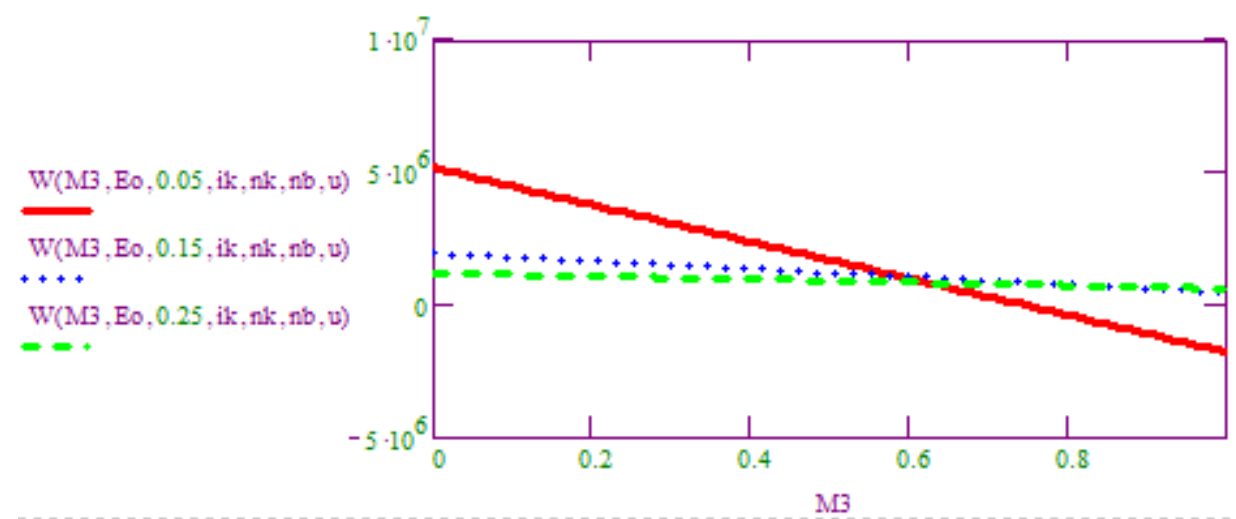

Fig. 3. Dependence of purchaser's benefits, in present-value terms, on the transaction LTV ratio (M3), at the rates of return, ib, equaling $5 \%, 15 \%$ and $0.25 \%$. Source: own study.

Thus, the value of purchaser's benefits decreases with an increase in the transaction leverage (LTV ratio) and can become negative after a certain LTV threshold. This means that a purchaser (investor) 
may incur losses in the future in the case of an insufficiently well-thought-through investment decision. His share of money capital, $(1-M) V$, invested in the purchase of the property, will not only not bring income, but, on the contrary, will be depleted by loan-amortization outgoings due to the creditor.

While an increase in the share of borrowed funds (LTV) is linearly related to the decrease in the present value of the purchaser's benefits, an increase in the rates of return, for example, within the range of $\mathrm{ibb}:=0.04,0.05 . .0 .5$, (see Fig.4) translates, first, to a sharp increase in the present value of purchaser's benefits and, then, to a smooth decline. Interestingly enough, there consequently exists an optimal rate of return in the purchaser's investment opportunity set which maximizes the present value of the purchaser's benefits and which can benefit the purchaser most in the transactional context.

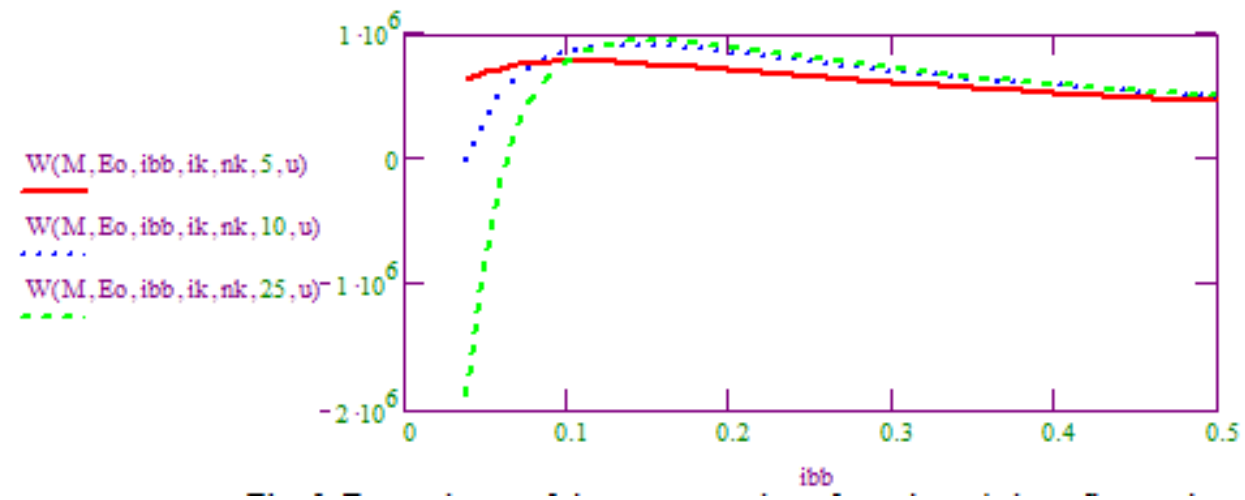

Fig. 4. Dependence of the present value of purchaser's benefits on the investment-opportunity-set rates of return, given different holding periods of 5, 10 and 15 years. Source: own study.

Even more pronounced is the dependence of the present value of purchaser's benefits on the length of the holding period. Let us assume, in the example, that the duration of the holding period ranges from $\mathrm{nbb}:=0,0.2$.. 40 years., then, the higher the interest rate on the loan, the more disadvantaged the purchaser (property investor). In Fig 5, the middle curve (in black) illustrates the dependence of the investor's share of invested capital on the projected holding period; other things being equal, this dependence is, in comparison, markedly less non-linear in its shape than the associated dependencies for $W$.

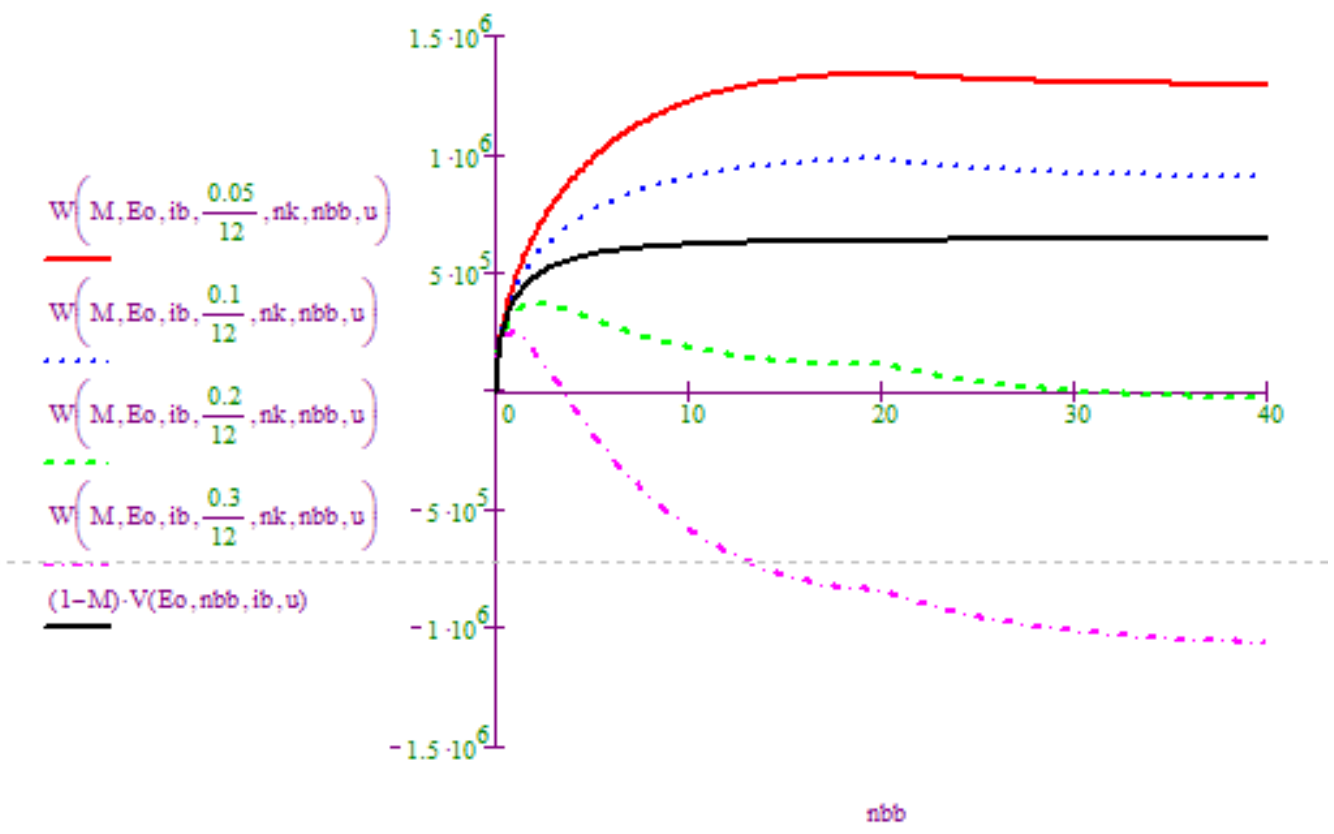

Fig. 5. The dependence of the present value of purchaser's benefits $W$ on the duration of the holding period, at different (annual) interest rates on the loan (monthly loan amortization pattern assumed): 


\section{$1-\mathrm{ik}=0.05 ; 2-\mathrm{ik}=0.1 ; 3-\mathrm{ik}=0.2 ; 4-\mathrm{ik}=0.3 ; 5-(1-\mathrm{M}) \times \mathrm{V}(\mathrm{Eo}, \mathrm{nb}, \mathrm{ib}, \mathrm{u})$-purchaser's invested capital. Source: own study.}

It can be seen from the Figure that if the loan rate exceeds the property market rate of return (rates in the applicable investment opportunity set), then the purchaser should expect losses from transacting under these conditions. The purchaser, thus, counts on exploiting the inverse situation.

In financial economics and property appraisal theory, the concept of "leverage" is given some

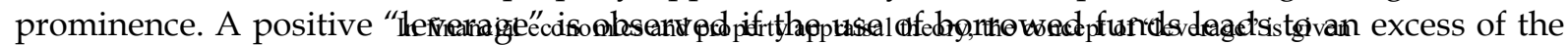

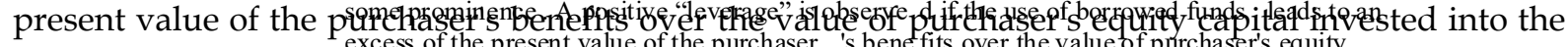

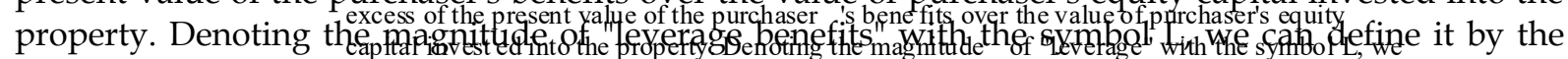
following formula: can define it by the following formula:

$$
\mathrm{L}(\mathrm{M}, \mathrm{Eo}, \mathrm{ib}, \mathrm{ik}, \mathrm{nk}, \mathrm{nb}, \mathrm{u}):=\frac{\mathrm{W}(\mathrm{M}, \mathrm{Eo}, \mathrm{ib}, \mathrm{ik}, \mathrm{nk}, \mathrm{nb}, \mathrm{u})-(1-\mathrm{M}) \cdot \mathrm{V}(\mathrm{Eo}, \mathrm{nb}, \mathrm{ib}, \mathrm{u})}{(1-\mathrm{M}) \cdot \mathrm{V}(\mathrm{Eo}, \mathrm{nb}, \mathrm{ib}, \mathrm{u})}
$$

As is evident from this formulation, leverage, as defined, shows an excess of the present value of purchasers' benefits over the purchaser's invested capital. Given the terms of our example: $M=0,7$; $\mathrm{Eo}=30000 \mathrm{CU} ; \mathrm{ib}=0.14 ; \mathrm{ik}^{*} 12=0,1 ; \mathrm{nk} / 12=20 ; \mathrm{nb}=10 ; \mathrm{u}=-0,1$, the associated leverage value $\mathrm{L}$ is positive: $\mathrm{L}(\mathrm{M}, \mathrm{Eo}, \mathrm{ib}, \mathrm{ik}, \mathrm{nk}, \mathrm{nb}, \mathrm{u})=0.464$.

This means that, over the course of 10-year holding period, the purchaser can count on the receipt of income, the present value of which exceeds in 1.464 times the amount of own funds invested by the purchaser into the transaction. If, on the other hand, the market/investment-opportunity-set rate of return sustains a change for some reasons (say, down to $i b=0.08$ ), then the value of leverage benefits is also liable to change (see Fig. 6).

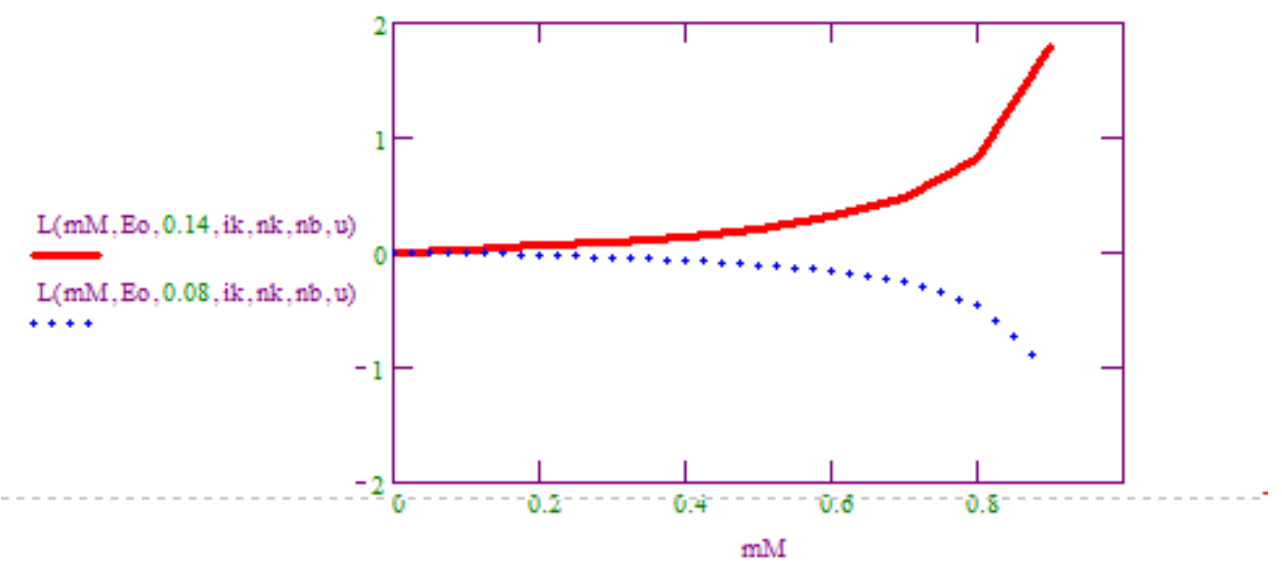

Fig. 6. Dependency of the value of leverage benefits $\mathrm{L}$ on the LTV ratio $(\mathrm{mM}=\mathrm{M})$ at different annual market rates of return: $i b=0.14 ; i b=0.08$. Source: own study.

It ought to be noticed that if no borrowings are used by the purchaser ( $\mathrm{LTV}=\mathrm{M}=0$ ), they receive neither an additional gain, nor sustain a loss. Thus, the possibility of gaining additional profit solely due to the use of borrowed funds is quite an attractive proposition, being the reason why the majority of large-scale property investment transactions are funded with an element of debt.

\subsubsection{Determining the value of property under the traditional mortgage-equity analysis techniques: derivation of the Ellwood formula}

What is the (market) value of a subject property, given the fact that the purchaser (buyer, investor) attracts loanable funds, i.e. uses borrowings as a transaction funding tool? At first glance, it may seem that the value of the property is in no way dependent on whether the buyer borrows funds to transact or not, because the seller, in principle, is hardly interested to what extent and from which sources the buyer borrows their funds. From this point of view, the market value of the property is calculated by the formula (9)-10) and is equal to $\mathrm{V}(\mathrm{Eo}, \mathrm{nb}, \mathrm{ib})=2066523$ currency units.

However, there is a different point of view, although, as will be seen, not an indisputable one. It is generally accepted that the predominant force on the real estate markets are the buyers and investors who use borrowed funds to lever transactions ("seek leverage") and, therefore, it is they who mainly determine demand for property and significantly affect the formation of the property value (e.g. see 
KPMG (2018), pp.18-26, for review of real estate related lending in Eastern Europe, including Poland). Secondly, there is a fairly developed system of lending to buyers by sellers themselves in order to obtain not only the proceeds from selling the property, but also generate income from the provision of loans. This fact also enhances the validity of this point of view. In addition, this view is widely shared, at least since the days of mortgage-equity analysis developed by Ellwood (1977) and Ackerson (1970), by American appraisers, who have accumulated a solid historic experience of appraisal activities (Friedman \& Ordway, 1989; Epley, 2007).

Based on this position, the (market) value of the property is calculated by adding the present value of the investor's expected income stream and residual proceeds from the resale of the property (after extinguishing the remaining debt balance) to the original principal of the mortgage loan (though this is a strong assumption, by definition, since it is implicitly assumed that the property (market) value should be determined by the sum of what an investor now (presently) has to buy the property with and what $\mathrm{s}$ /he will have gained from their possession in the future; on this assumption, as we will show, rests the entire body of Ellwood's mortgage-equity analysis to property valuation).

Thus, let the value of an income-producing property, VI, under the above assumption that this value represents the sum of the present value of holding-period benefits accruing to the buyer (investor) and the capital available to him (on credit) for purchasing the property, be determined under the following formula:

$$
\mathrm{VI}=\mathrm{W}(\mathrm{M}, \mathrm{Eo}, \mathrm{ib}, \mathrm{ik}, \mathrm{nk}, \mathrm{nb}, \mathrm{u})+\mathrm{M} \times \mathrm{VI}(\mathrm{Eo}, \mathrm{nb}, \mathrm{ib}, \mathrm{u})
$$

or:

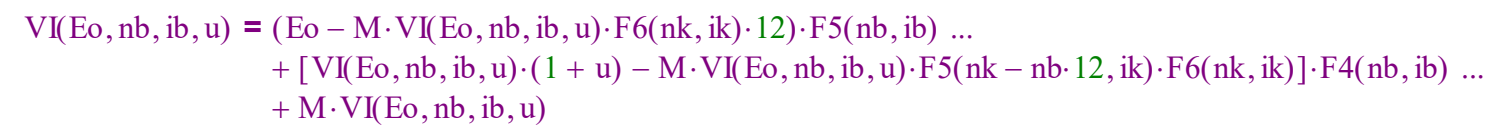

Solving (17) relative to VI - the market value of income-producing property sought under the mortgage equity capitalization technique, we obtain:

$$
\begin{aligned}
& \operatorname{VI}(M, E o, i b, i k, n k, n b, u):=F 5(n b, i b) \cdot \frac{\text { Eo }}{1+12 \cdot F 5(n b, i b) \cdot M \cdot F 6(n k, i k)-F 4(n b, i b)-F 4(n b, i b) \cdot u \ldots} \\
& +\mathrm{F} 4(\mathrm{nb}, \mathrm{ib}) \cdot \mathrm{M} \cdot \mathrm{F} 5(\mathrm{nk}-12 \cdot \mathrm{nb}, \mathrm{ik}) \cdot \mathrm{F} 6(\mathrm{nk}, \mathrm{ik})-\mathrm{M}
\end{aligned}
$$

Evaluating this expression for our example yields: VI( M, Eo, ib, ik, nk, nb, u) = 2532326.983.

As can be seen, the value of the property estimated under the above equity capitalization technique having regard to the leverage is different from its value absent the possibility of leverage (V( Eo, nb, $\mathrm{ib}, \mathrm{u})=2066523.398)$.

Essentially, Formula (18) represents the main estimation engine for the traditional mortgage equity analysis, albeit it is not used there as such (Friedman \& Ordway, 1989; Saunder, 2009). An analysis of Formula (18) indicates that the value of the property estimated having regard to the leverage tends to increase or decrease as the leverage (LTV) ratio rises, depending on the loan interest rate (see Fig. 7). It should be noted that the value of the property remains almost unaffected by leverage $(\mathrm{LTV}=\mathrm{M})$ in the case of equivalency between the opportunity market rate of return and the loan rate.

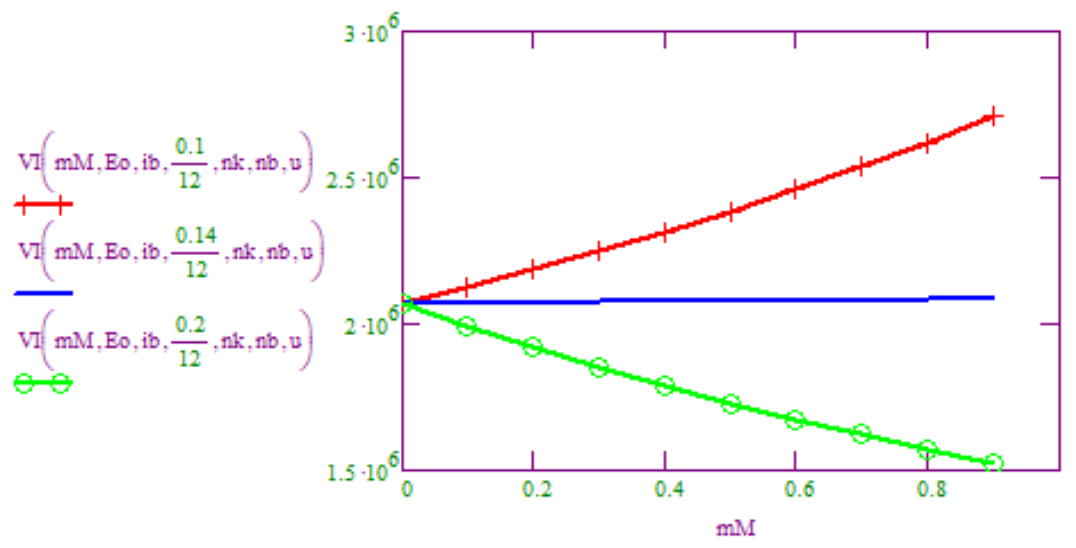


Fig. 7. Effects of the LTV ratios $(\mathrm{mM})$ and loan rates on the value of subject property: $\mathrm{iK}=0.1$ annual rate with monthly amortization payments; and ik $=0.14$, ik $=0.2$ on the same terms. Source: own study.

Consequently, the higher the loan rate the less funds investors will be prepared to attract, with the values of such properties, therefore, tending to decrease.

Formula (18) is key to mortgage-equity appraisal analysis. At the same time, its somewhat cumbersome nature and the need to use tables to determine values for the three functions of dollar F4, F5, and F6 during the time of low penetration of computer technology (in the 1960s and 1970s) moved the appraisers to look for simpler algorithms for determining the value of property having regard to its leverage. The relation (11), in accordance with which the value of the subject is equal to the quotient of dividing the net periodic income Eo by the market rate of return $i b$, turned out to be remarkable in this sense. However, how was it possible to bypass the restricting assumptions incidental to the use of this formula, namely, that the value of the property should remain unchanged over time or that the property holding period should be infinite? There was an idea, instead of using the market rate of return, ib , to use such a rate that, when dividing the net operating income Eo by it, returns exactly the same results as formula (18) would give.

This rate was obtained by L.V. Ellwood and called the overall property capitalization rate. Its usual notation is Ro. Ellwood's reasoning can be reproduced as follows (see Lombardo (1998), but the emphasis on the distinction between $\mathrm{V}$ and $\mathrm{VI}$ is ours).

Consider Formula (18), which allows to determine the value of property - VI , which brings annual operating income - Eo, and for the purchase of which borrowed funds $\mathrm{M}^{*} \mathrm{VI}$ were used. If the denominator of this formula (Formula 18), divided by F5 (nb, ib), is designated as Ro, then we obtain a relation similar to (11).

$$
V I=\frac{E o}{R o}
$$

By multiplying the numerator and denominator of the RHS of (18) by F6(nb, ib), the F5 (nb, ib) term in the numerator of (18) cancels out and becomes identical with the numerator of (19), while the denominator in Formula (18) can be transformed thus to obtain a simplified expression for Ro:

$$
\begin{aligned}
\text { Ro }= & F 6(n b, i b)+12 \cdot F 6(n k, i k) \cdot M-F 4(n b, i b) \cdot F 6(n b, i b)-F 4(n b, i b) \cdot F 6(n b, i b) \cdot u ~ \ldots \\
& +F 4(n b, i b) \cdot F 6(n b, i b) \cdot M \cdot F 5(n k-n b \cdot 12, i k) \cdot F 6(n k, i k)-M \cdot F 6(n b, i b)
\end{aligned}
$$

At this stage of transformation we have only considered that the money functions F5 and F6 are reciprocal, that is, $\mathrm{F}^{*} \mathrm{~F} 6=1$.

Transforming further:

$$
\begin{aligned}
\mathrm{Ro}= & F 6(n b, i b)+12 \cdot F 6(n k, i k) \cdot M-F 3(n b, i b)-F 3(n b, i b) \cdot u \ldots \\
& +F 3(n b, i b) \cdot M \cdot F 5(n k-n b \cdot 12, i k) \cdot F 6(n k, i k)-M \cdot F 6(n b, i b)
\end{aligned}
$$

Now we have accounted for the fact that the money functions F4 and F6 are associated by a relationship $\mathrm{F} 4 * \mathrm{~F} 6=\mathrm{F} 3$. Rearranging the terms:

$$
\begin{aligned}
& \text { Ro }=F 6(n b, i b)-F 3(n b, i b) \ldots \\
& -M \times(F 6(n b, i b)-F 3(n b, i b) \times F 5(n k-n b \times 12, i k) \times F 6(n k, i k)-12 \times F 6(n k, i k)) \ldots \\
& -F 3(n b, i b) \times u
\end{aligned}
$$

Expressing the residual balance of the loan $\mathrm{BAL}:=\mathrm{F} 5(\mathrm{nk}-\mathrm{nb} \cdot 12$, ik). F6(nk, ik) via an amortized fraction of the İaian amortized fraction of the loan

$$
\begin{aligned}
& \mathrm{P}:=1-\mathrm{BAL} \text {, and considering that F6-F3=i, we obtain: } \\
& \mathrm{Ro}:=\mathrm{ib}-\mathrm{M} \cdot(\mathrm{ib}+\mathrm{P} \cdot \mathrm{F} 3(\mathrm{nb}, \mathrm{ib})-12 \cdot \mathrm{F} 6(\mathrm{nk}, \mathrm{ik}))-\mathrm{F} 3(\mathrm{nb}, \mathrm{ib}) \cdot \mathrm{u}
\end{aligned}
$$

Evaluating the overall capitalization rate in our example: ${ }^{R o}=0.118$, we crosscheck the resulting value against Equation (18):

$$
\frac{\text { Eo }}{\text { Ro }}=2532326.983
$$

Let's re-designate the formula parameters with a more conventional notation deriving from ELLWOOD (1977) and not associated with TAPA. The plethora of terms used often baffles property appraisers. Thus, the average market/investment-opportunity-set rate of return $\mathbf{i b}$ is often called the "equity yield rate" and designated as Ye. 
The loan to value ratio is denoted as $\mathbf{M}$, which is same as above in the text.

F3(n,i) money function is called the sinking fund factor, abbreviated as SSF (sinking fund factor), and often designated as $1 / \mathrm{Sn}$.

F6(n,i) money function with the loan term nk and loan interest rate ik shows, in this instance, the ratio of loan amortization instalments (debt service) to the original loan principal advanced, and is called the mortgage constant, or mortgage/debt capitalization rate. It is frequently denoted as $\mathbf{R m}$, and the factor "12" in Formula (2.13) is used to convert monthly debt service into the annual one.

The cumulative property value change over the holding period $\mathbf{u}$ is denoted by symbol $\Delta \mathbf{o}$. The relations between the prior TAPA notation and the conventional Ellwood formula notation are summarized in Table 1 of this Paper.

Table 1

Correspondence between the TAPA and Ellwood mortgage equity analysis notation

\begin{tabular}{|c|c|c|}
\hline Notation & Meaning & Relations \\
\hline $\begin{array}{ll}\text { VI, } & \text { Vo, } \\
\text { PV } & \end{array}$ & Property Value, Current value, Present value & \\
\hline ib, Ye & $\begin{array}{l}\text { Market rate of return, equity yield rate }{ }^{6}- \\
\text { expected rate of return in the market/ } \\
\text { opportunity investment set acceptable } \\
\text { both to the seller and the purchaser in a } \\
\text { specific transaction. }\end{array}$ & \\
\hline ik, Ym & Loan interest rate, mortgage yield rate & \\
\hline $\mathbf{M}$ & $\begin{array}{l}\text { Loan to value ratio - ratio of the original loan } \\
\text { principal to the } \\
\text { property value (LTV). }\end{array}$ & \\
\hline Yo & Overall yield rate & $\mathrm{Yo}_{\mathrm{o}}=\mathrm{Ym}^{\prime} \mathrm{M}+\mathrm{Ye}^{\prime}(1-\mathrm{M})$ \\
\hline $\mathbf{n b}$ & Purchaser's (investor's) holding period & \\
\hline nk & $\begin{array}{l}\text { Term of the loan provided by creditor to the } \\
\text { property purchaser }\end{array}$ & \\
\hline Eo, NOI & $\begin{array}{l}\text { Periodic annual net operating income from } \\
\text { using the property distributable between the } \\
\text { purchaser and creditor: property } \\
\text { rental income less all the property operating } \\
\text { (servicing) expenses. }\end{array}$ & \\
\hline $\mathbf{u}, \Delta_{\mathrm{o}}$ & $\begin{array}{l}\text { Cumulative change in the value of the } \\
\text { (subject) property expected to occur over the } \\
\text { holding period: } \\
\text { increase }(+) \text {; decrease }(-)\end{array}$ & $\mathrm{u}=\left(\mathrm{S}_{\mathrm{res}} / \mathrm{V}\right)-1$ \\
\hline $\mathbf{L}$ & $\begin{array}{l}\text { Financial leverage - as described in this } \\
\text { Paper, L is defined as a ratio characterizing } \\
\text { an excess of the present value of purchaser's } \\
\text { expected benefits (holding period income } \\
\text { stream + reversion) over the purchaser's } \\
\text { invested capital }\end{array}$ & $\begin{array}{l}\mathrm{L}=((\mathrm{Eo}-\mathrm{M} \times \mathrm{V} \times \mathrm{F} 6(\mathrm{nk}, \mathrm{ik})) \\
\times \mathrm{F} 5(\mathrm{nb}, \mathrm{ib})+(\mathrm{V} \times(1+\mathrm{u})- \\
\mathrm{M} \times \mathrm{V} \times \mathrm{F} 5(\mathrm{nk}- \\
\mathrm{nb}, \mathrm{ik}) \times \mathrm{F} 6(\mathrm{nk}, \mathrm{ik})) \times \mathrm{F} 4(\mathrm{nb}, \mathrm{ib})) / \\
((1-\mathrm{M}) \times \mathrm{V})-1\end{array}$ \\
\hline $\mathbf{R m}$ & $\begin{array}{l}\text { Mortgage capitalization rate (mortgage } \\
\text { constant, mortgage rate) - ratio of the annual } \\
\text { debt service to the original principal of the } \\
\text { loan (at inception). }\end{array}$ & $\mathrm{Rm}=\mathrm{F} 6(\mathrm{nk}, \mathrm{ik})$ \\
\hline
\end{tabular}

\footnotetext{
${ }^{6}$ Since the mortgage- equity capitalization methods use American terminology, the notion of yield in their context shouldn't be confused with the notion of market yield as developed in TAPA (Michaletz \& Artemenkov, 2018; Michaletz \& Artemenkov, 2019). In the mortgage-equity context, yield conveys the concept of the overall rate-of return (both on the current income factor and the capital value account), not just the current return component.
} 


\begin{tabular}{|c|c|c|}
\hline $\operatorname{Re}$ & $\begin{array}{l}\text { Equity capitalization rate, cash on cash rate -- } \\
\text { ratio of the property annual net operating } \\
\text { income accruing to the purchaser to their } \\
\text { original invested capital }\end{array}$ & $\begin{array}{l}\mathrm{Re}=(\mathrm{Eo}-\mathrm{M} \times \mathrm{V} \times \mathrm{Rm}) /((1-\mathrm{M}) \times \mathrm{V}) \\
\mathrm{Re}=\mathrm{ib}+\mathrm{L} \times \mathrm{F} 6(\mathrm{nb}, \mathrm{ib})- \\
-\mathrm{F} 3(\mathrm{nb}, \mathrm{ib}) \times(\mathrm{M} \times(1-\mathrm{F} 5(\mathrm{nk}-\mathrm{nb}, \mathrm{ik}) \\
\times \mathrm{F} 6(\mathrm{nk}, \mathrm{ik}))+\mathrm{u}) /(1-\mathrm{M}) \\
\mathrm{Re}=(\mathrm{Ro}-\mathrm{M} \times \mathrm{Rm}) /(1-\mathrm{M})\end{array}$ \\
\hline Ro & Overall capitalization rate & $\begin{array}{l}\mathrm{Ro}=\mathrm{Eo} / \mathrm{V} \\
\mathrm{Ro}=\mathrm{ib}-\mathrm{M} \times(\mathrm{ib}+(1-\mathrm{F} 5(\mathrm{nk}-\mathrm{nb}, \mathrm{ik}) \\
\times \mathrm{F} 6(\mathrm{nk}, \mathrm{ik})) \times \\
\mathrm{F} 3(\mathrm{nb}, \mathrm{ib})-\mathrm{F} 6(\mathrm{nk}, \mathrm{ik}))- \\
-\mathrm{F} 3(\mathrm{nb}, \mathrm{ib}) \times \mathrm{u}+\mathrm{L} \times(1-\mathrm{M}) \times \mathrm{F} 6(\mathrm{nb}, \mathrm{ib}) \\
\mathrm{Ro}=\mathrm{Rm} \times \mathrm{M}+\operatorname{Re} \times(1-\mathrm{M})\end{array}$ \\
\hline
\end{tabular}

Source: own study.

Thus, re-writing Formula (23) using "new" notation transforms it into the conventional-looking Ellwood formula, known from many textbooks (e.g. Friedman \& Ordway, 1989):

$$
\mathrm{Ro}=\mathrm{Ye}-\mathrm{M} \cdot(\mathrm{Ye}+\mathrm{P} \cdot \mathrm{SSF}-\mathrm{Rm})-\mathrm{SSF} \cdot \mathrm{u}
$$

Formula (24) can be recast to look as follows:

$$
\mathrm{Ro}=\mathrm{M} \cdot \mathrm{Rm}+(1-\mathrm{M}) \cdot \mathrm{Ye}-\mathrm{M} \cdot \mathrm{P} \cdot \mathrm{SSF}-\mathrm{SSF} \cdot \mathrm{u}
$$

as has been done by Ackerson (1970).

Ellwood's formula (24) somewhat simplifies estimation of the value of income-producing property purchased with borrowed funds, although, in the age of universal computing power, this hardly matters.

It should be noted that the traditional technique of mortgage-equity analysis is based on the assumption that the future net operating income expected from subject property, Eo , and the rates of return ib (or Ye) remain unchanged. These assumptions severely limit the application possibilities for the obtained formulas and force one to rely on even more elaborate mortgage-equity formulas with J and $\mathrm{K}$ loads to allow for changing patterns in the subject property income over the holding period (which appeared in the $1970 \mathrm{~s}$ starting from the third edition of The Ellwood' Tables, according to Jefferies (2017)).

Let us consider a few more ways to determine the overall capitalization rate Ro.

The band-of-investment method is popular within the income approach valuation theory (Friedman \& Ordway, 1989), according to which the overall capitalization rate Ro is determined as the weighted average of the mortgage capitalization rate $\mathrm{Rm}$ and the equity capitalization rate Re:

$$
\mathrm{Ro}=\mathrm{M} \cdot \mathrm{Rm}+(1-\mathrm{M}) \cdot \mathrm{Re}
$$

where: $\mathrm{Rm}:=\mathrm{F} 6(\mathrm{nk}, \mathrm{ik}) \cdot 12$ is the mortgage constant. Evaluating, $\mathrm{Rm}=0.116$ in our example.

Equity capitalization rate $\mathrm{Re}$ is the ratio of annual net operating income receipts by the investor (net of the debt service) to their original equity investment (invested capital):

$$
\operatorname{Re}:=\frac{\text { Eo }-\mathrm{M} \cdot \mathrm{VI}(\mathrm{M}, \mathrm{Eo}, \mathrm{ib}, \mathrm{ik}, \mathrm{nk}, \mathrm{nb}, \mathrm{u}) \cdot \mathrm{F} 6(\mathrm{nk}, \mathrm{ik}) \cdot 12}{(1-\mathrm{M}) \cdot \mathrm{VI}(\mathrm{M}, \mathrm{Eo}, \mathrm{ib}, \mathrm{ik}, \mathrm{nk}, \mathrm{nb}, \mathrm{u})}
$$

Evaluating, $\operatorname{Re}=0.125$.

In comparing the magnitude of the equity capitalization rate Re with the equity rate-of-return in the investor's investment opportunity set $\mathrm{Ye}(\mathrm{Ye}:=\mathrm{ib})$, it becomes clear that Re also accounts for the debt servicing component. A relation between these two variables can be found by comparing righthand sides of the band-of-investment and Ackerson formulas:

$$
\mathrm{M} \cdot \mathrm{Rm}+(1-\mathrm{M}) \cdot \mathrm{Re}=\mathrm{M} \cdot \mathrm{Rm}+(1-\mathrm{M}) \cdot \mathrm{Ye}-\mathrm{M} \cdot \mathrm{P} \cdot \mathrm{SSF}-\mathrm{SSF} \cdot \mathrm{u}
$$

Hence, 


$$
\operatorname{Re}=\mathrm{Ye}-\mathrm{SSF} \cdot \frac{\mathrm{M} \cdot \mathrm{P}+\mathrm{u}}{1-\mathrm{M}}
$$

or

$$
\operatorname{Re}:=\mathrm{Ye}-\mathrm{F} 3(\mathrm{nb}, \mathrm{ib}) \cdot \frac{\mathrm{M} \cdot(1-\mathrm{F} 5(\mathrm{nk}-\mathrm{nb} \cdot 12, \mathrm{ik}) \cdot \mathrm{F} 6(\mathrm{nk}, \mathrm{ik}))+\mathrm{u}}{1-\mathrm{M}}
$$

Evaluating Re expressed this way, yields $\operatorname{Re}=0.125$, which accords with the evaluation for Formula (27).

The equity capitalization rate Re can be represented as a function of the overall capitalization rate Ro and the mortgage capitalization rate $\mathrm{Rm}$ based on a solution for the band-of-investment formula:

$$
\operatorname{Re}:=\frac{\mathrm{Ro}-\mathrm{M} \cdot \mathrm{Rm}}{1-\mathrm{M}}
$$

In practical terms, the equity capitalization rate Re allows to compute a share of the net operating income from property E accruing to the purchaser (investor) after allowing for the debt service in favor of the creditor in the transaction. For example, if the capital invested by both the purchaser and their creditor into the purchase of the subject property is:

VI( M, Eo, ib, ik, nk, nb, u) = 2532326.983, then

the annual income of the investor is:

$$
\operatorname{Re} \cdot(1-M) \cdot \operatorname{VI}(M, \text { Eo, ib, ik, nk, nb, u })=94724.971
$$

and that of his creditor is:

$$
\mathrm{Rm} \cdot \mathrm{M} \cdot \mathrm{VI}(\mathrm{M}, \mathrm{Eo}, \mathrm{ib}, \mathrm{ik}, \mathrm{nk}, \mathrm{nb}, \mathrm{u})=205275.029
$$

Which, in total, adds up to the 300000 currency units of income, as assumed in our example.

Thus, the annual net operating income generated by the property is distributed between the purchaser and the creditor according to the mortgage and equity capitalization rates. Equity capitalization rate $\mathrm{Re}$, at a given rate of return $\mathrm{Ye}$, can have various patterns of dependency on the LTV ratio M (see. Fig. 8).

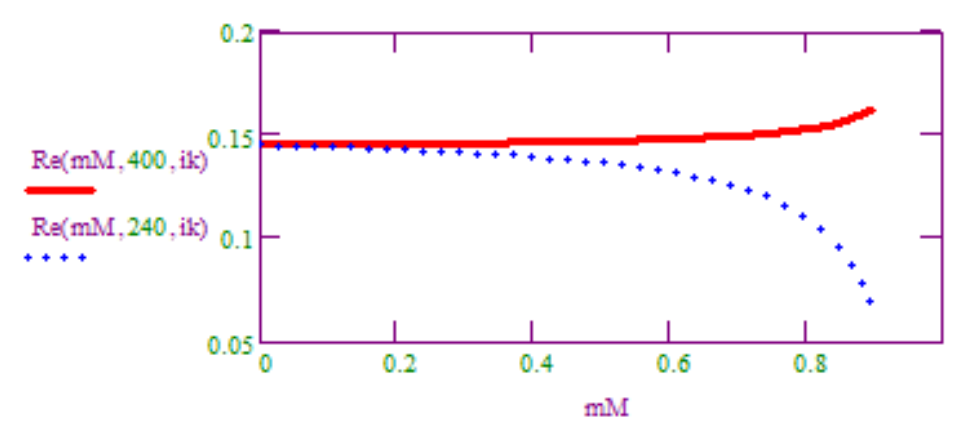

Fig. 8. Equity capitalization rate Re as a function of LTV ratio (mM) for various loan terms: solid line nk=400 months; dotted line - nk=240 months. Source: own study.

This example, once again, demonstrates the effect of financial leverage. If the investor succeeds in convincing the lender to increase the loan term from 240 months to 400 months, then it becomes expedient for the investor to ask the creditor for as large LTV ratio, M, as possible. The same results are obtainable if the band-of-investment formula (26) is employed.

Of some interest is the dependence of Re on the property holding period (see Fig. 9).

Under the conditions of this example, the investor can, by reducing the holding period for the purchased property to several weeks or months, receive $40-50 \%$ or more of the profit on the own capital invested into the purchase transaction. The rate of profit increases significantly with an increase in the loan-to-value ratio $\mathrm{M}$ and can reach high values. Noteworthy is a slight increase in the equity capitalization rate in the range $\mathrm{nb}>\mathrm{nk}$, i.e. if the property holding period exceeds the loan term.

A different pattern is observed, however, when the investor is dealing with a property the value of which increases with time $(u>0)$. In connection with the dependence illustrated by Fig 9., it should be noted that, at certain magnitudes of the property value change over the holding period (i.e. at certain 
(positive) values of $\mathrm{u}$ ), the curve has a humped shape, suggesting the optimality of certain holding periods in terms of achievable Re rates. This is a matter for subsequent exploration into the investment properties of the Ellwood approach to valuation.

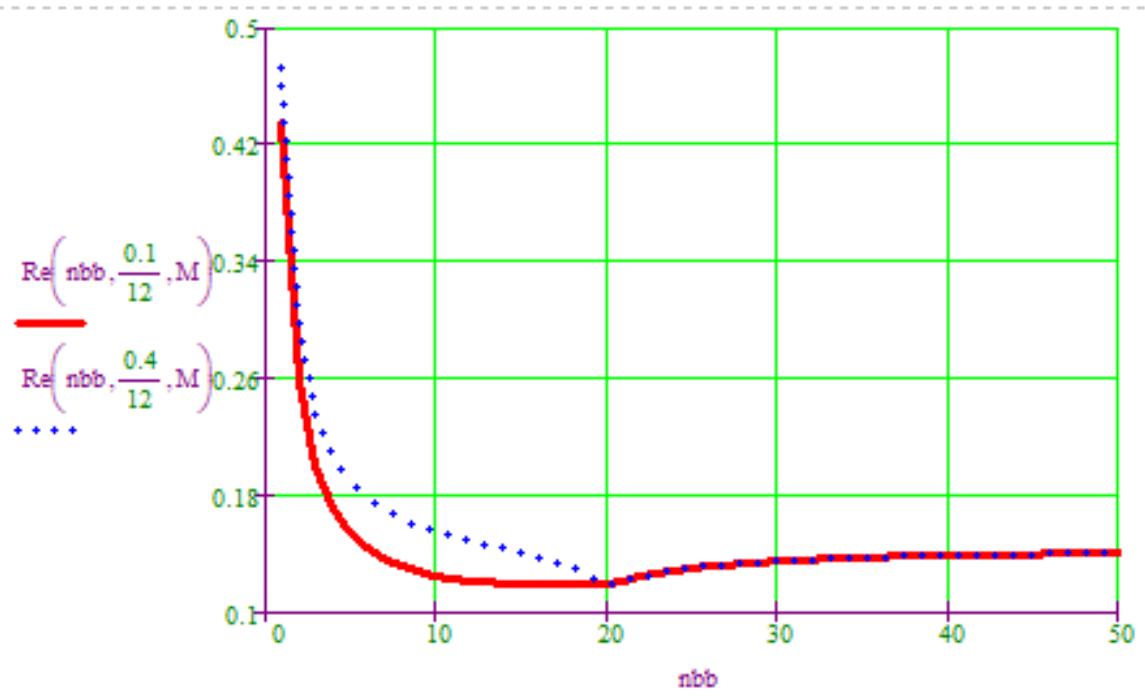

Fig. 9 Equity capitalization rate Re as a function of the property holding period nbb, given the loan rates $\mathrm{ik}=0.1$ (solid line) and $\mathrm{ik}=0.4$ (dotted line). Source: own study.

In the actual valuation practice, and when a change in the property's prospective value is not assumed or neglected for reasons of simplicity, one occasionally comes across such band-ofinvestment method applications where it is assumed that the overall capitalization rate Ro equals the weighted average of the mortgage and equity yield rates Yo:

Evaluating $\wedge$ Yo $=0.112$.

$$
\begin{aligned}
& \text { Yo: }:=i b \cdot(1-M)+i k \cdot M \cdot 12 \\
& Y_{0}=\mathbf{I}
\end{aligned}
$$

However, it should be emphasized that Ro and Yo are different notions. The resulting error $\mathrm{d}=$ RoYo in determining the (correct) overall capitalization rate, Ro, substantially increases with the shortening of the assumed holding periods for the property, $\mathrm{nb}$.

Last but not least of what remains to be said of the Ellwood formula is that its leverage benefits ratio $(\mathrm{L})$ is always zero for the purchaser/investor, $\mathrm{L}=0$, since the property pricing process envisaged under the formula is such that the equity investment of the purchaser $(1-\mathrm{M})^{*} \mathrm{VI}$ is priced in as the purchaser's benefits W. This emphasizes the point again that the Ellwood formula is an entirely demand-driven formula which is prone to obviating any gains-from-trade to the investor, which consequently accrue to the seller of the property. In section 3.2.3, we propose an extension of the Ellwood formula which takes care of alleviating this feature of the Ellwood formula.

\subsubsection{A proposal for the fixed-leverage-benefits approach to property valuation}

The basis of the traditional technique underlying mortgage-equity analysis is the assumption that the value of income-producing property is largely formed under the influence of purchasers/investors who are able to pay down a fraction 1-M of the property value and receive income streams from its use in the future. This leaves out of account the natural desire on the part of investors to be more specific in their evaluation of the benefits on account of the mortgage component.

The purchaser (investor) always strives to ensure that the amount invested in the purchase (the initial investment) is less than the present value of all the benefits expected from owning the property over the course of the projected holding period. Therefore, it can be assumed that the vast majority of transactions are carried out with a positive "leverage" for buyers. Obviously, the probability that the value of leverage benefits, L, (see formula 16) will be assuming extreme values close to zero or too large -- is rather low. Then it may be possible to predict the values of leverage benefits (L) for specific properties and in specific regions by statistical method. On the other hand, the value of leverage benefits L can act as an investor's demanded input to the process of property valuation. One way or 
another, if in Expression (16) the value of L is assumed to be known, then it becomes possible to solve Expression (16) for $\mathrm{V}$-- resulting in the following formula for valuing income-producing properties on the basis of the required leverage benefits $(\mathrm{L})$ :

$$
\begin{aligned}
\mathrm{V}(\mathrm{L}):=\mathrm{F} 5(\mathrm{nb}, \mathrm{ib}) & \frac{\mathrm{Eo}}{1+\mathrm{12} \cdot \mathrm{F} 5(\mathrm{nb}, \mathrm{ib}) \cdot \mathrm{M} \cdot \mathrm{F} 6(\mathrm{nk}, \mathrm{ik})-\mathrm{F} 4(\mathrm{nb}, \mathrm{ib})-\mathrm{F} 4(\mathrm{nb}, \mathrm{ib}) \cdot \mathrm{u} \ldots} \\
& +\mathrm{F} 4(\mathrm{nb}, \mathrm{ib}) \cdot \mathrm{M} \cdot \mathrm{F} 5(\mathrm{nk}-12 \cdot \mathrm{nb}, \mathrm{ik}) \cdot \mathrm{F} 6(\mathrm{nk}, \mathrm{ik})-\mathrm{M} \ldots \\
& +\mathrm{L} \cdot(1-\mathrm{M})
\end{aligned}
$$

Reflecting on formulas (16) and (33), it is possible to conclude that the above formula of fixedleverage-benefits valuation represents a generalization of the traditional mortgage-equity capitalization technique developed by ELLWOOD (1977) and ACKERSON (1970).

It follows from Formula (33) that the higher the value of leverage benefits $L$ demanded by the investor $(\mathrm{nL}:=-0.1,-0.09 . .0 .5)$, the lower value a property is appraisable at (see Fig. 10)

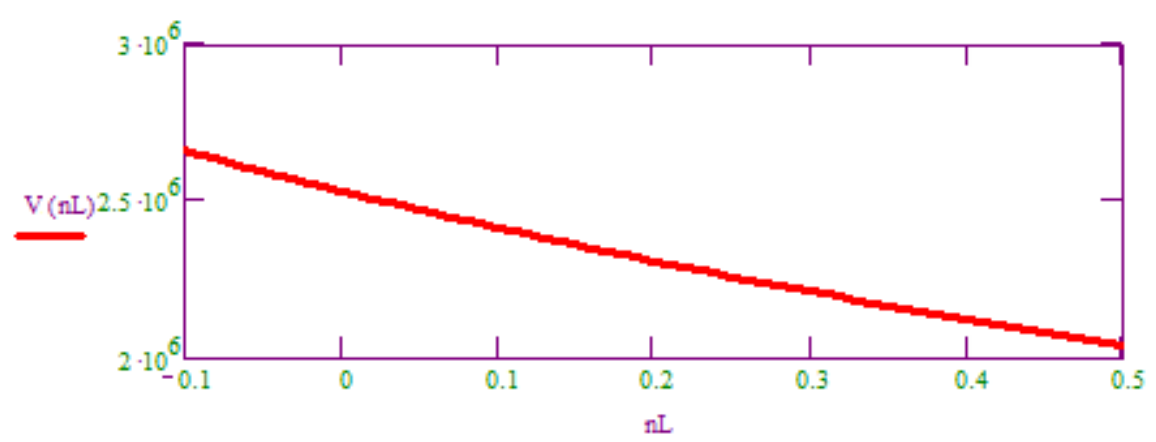

Fig. 10. Dependence of the value of subject property on different magnitudes of the leverage benefits $\mathrm{L}=\mathrm{nL}(-0.1 . .0 .5)$, at $\mathrm{u}<0)$. Source: own study.

At the level of leverage benefits $\mathrm{L}=0.15$, that is when typical market investors intend to have $15 \%$ excess of the present value of ownership benefits over their invested capital, the value of subject property will amount to $\mathrm{V}(0.15)=2360434.906$ currency units, which is less than under the Ellwood formula estimation.

Thus, accounting for the proposed fixed leverage benefits in the valuation formula results in some changes to the Ellwood and associated formulas:

For purposes of capitalizing the first-period net operating income from the property, Eo, into value, the overall capitalization rate for the proposed fixed-leverage-benefits approach should be determined according to this formula:

$$
\text { Ro :=ib - M×(ib + P×F3(nb,ib) - 12×F6(nk, ik)) - F3(nb, ib)×u + L×(1-M)×F6(nb, ib) }
$$

As can be seen, this formula differs from the conventional Ellwood formula for the overall capitalization rate by the addition of the last term only. Similarly, the equity capitalization rate in the proposed fixed-leverage-benefits approach is derivable as:

$$
\operatorname{Re}=\mathrm{Ye}+\mathrm{L} \cdot \mathrm{F} 6(\mathrm{nb}, \mathrm{ib})-\mathrm{F} 3(\mathrm{nb}, \mathrm{ib}) \cdot \frac{\mathrm{M} \cdot(1-\mathrm{F} 5(\mathrm{nk}-\mathrm{nb} \cdot 12, \mathrm{ik}) \cdot \mathrm{F} 6(\mathrm{nk}, \mathrm{ik}))+\mathrm{u}}{1-\mathrm{M}}
$$

or:

$$
\operatorname{Re}=\frac{\mathrm{Eo}-\mathrm{M} \cdot \mathrm{V}(\mathrm{L}) \cdot \mathrm{F} 6(\mathrm{nk}, \mathrm{ik}) \cdot 12}{(1-\mathrm{M}) \cdot \mathrm{V}(\mathrm{L})}
$$

\section{Empirical results}

Empirical results in this analytical Paper represent the derived formulas' evaluations. As can be seen from Section 3, care has been taken to check all the formulas by their evaluations in Mathcad 13.0 environment, yielding consistent results. As expected, the extended Ellwood formula, given the investor's goal of obtaining positive leverage benefits $(\mathrm{L}>0)$ in property valuation, will always yield valuations below the conventional Ellwood formula results, since, as we have shown, the underlying 
assumption in the conventional Ellwood formula is that $\mathrm{L}=0$, whilst the extended Ellwood formula derived in Section 3.2.3 allows for the achievement of positive leverage benefits by investors into property.

\section{Discussion and conclusions}

The Paper has shown a derivation for the Ellwood formula within the mortgage equity analysis to property valuation proceeding from TAPA's first principles. Such a derivation emphasizes the notion of leverage benefits, L, and shows that, under Ellwood, the net value of such benefits obtainable by the purchasers of a property is always zero-since when Ellwood is used for pricing a property, i.e. determining not just its investment, but its exchange value, it ensures a non-neutral split and transfer of leverage benefits in favor of the seller. Thus, the use of unmodified Ellwood framework is compatible only with the investment value (i.e. value-in-use) standard (on the buyer's side of analysis). Additionally, the Paper proposes a fixed- leverage-benefits valuation method which generalizes the Ellwood formula by taking into account a typical economic motivation of investors participating in the commercial property market to achieve a defined excess of the present value of their expected benefits over the equity capital invested into purchasing the property (such a motivation is always a commonplace notion present by default whenever property investment projects are evaluated with reference to NPV, IRR and other like measures). Such an extension of the conventional Ellwood framework can make its use compatible with a standard of the value-inexchange (fair/equitable or even the market value). Relations between the proposed extended valuation method and the Ellwood formula, as well as between the latter and the direct income capitalization approach are illustrated in Fig. 11.

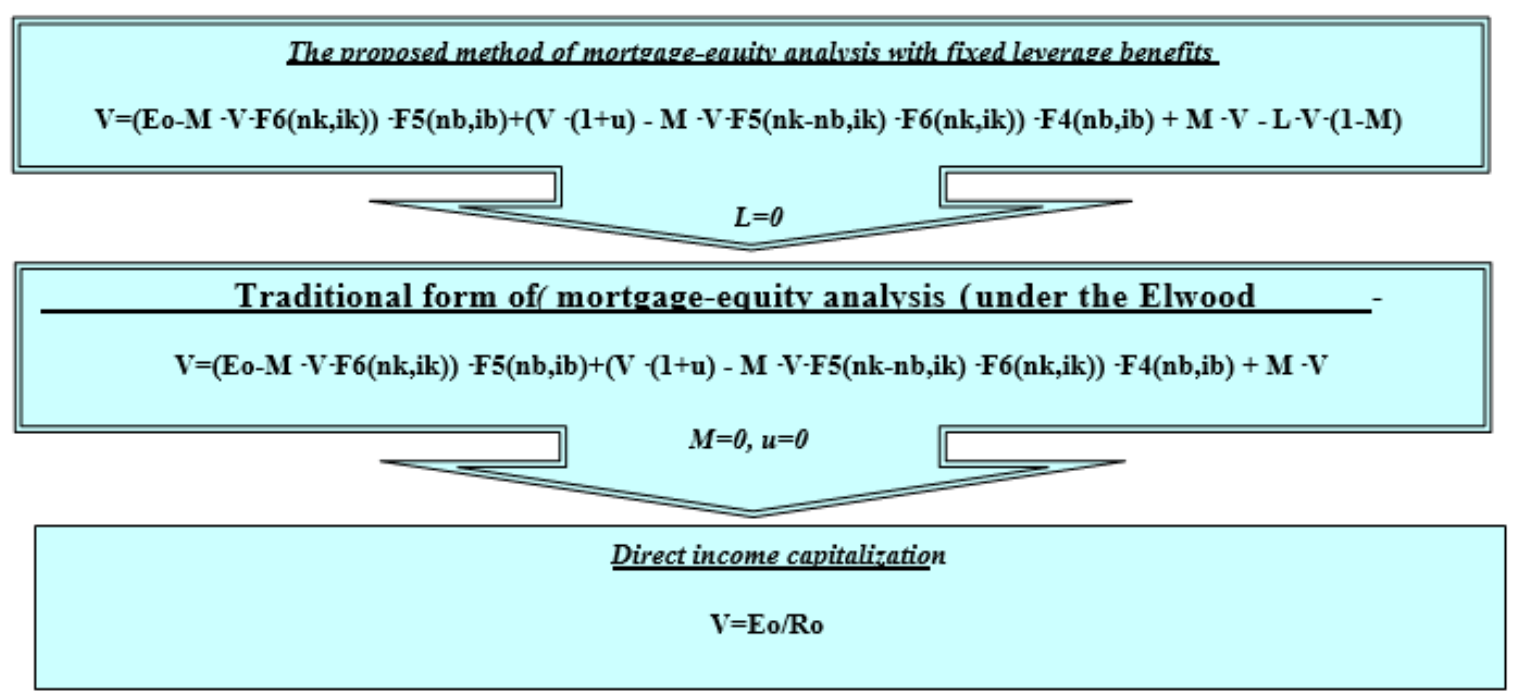

Fig. 11. Valuation methods for income-producing property. Source: own study.

\section{References}

Akerson, C. B. 1970. Ellwood Without Algebra. The Appraisal Journal, 38(2), 327.

Akerson, C.B. 2000. Capitalization Theory and Techniques. Second Edition. Chicago, Illinois. Appraisal Institute.

d'Amato, M., Siniak, N., \& Mastrodonato, G. (2019). "Cyclical assets" and cyclical capitalization. Journal of European Real Estate Research, 12(2), 267-288. https://doi.org/10.1108/JERER-05-2018$\underline{0022}$

Ellwood, L. W. (1977). Ellwood tables for real estate appraising and financing: containing both explanatory text and tables Cambridge, Mass.: Published for the American Institute of Real Estate Appraisers of the National Association of Realtors [by] Ballinger Pub. Co., Fourth edition, c1977. (First edition -1957)

Epley, Donald R. 2007. Impact of the Ellwood Approach on Value. The Appraisal Journal, 75 (3), 295297.

Galasuyk, V. V. (2018) Fair Exchange Value for Objects in Purchase-sale, Gift and Exchange Transactions', Art-Pres publishers, Dnipro, p.203, ISBN: 978-966-348-413-6. 
Fisher, I. (1930). The Theory of Interest: As Determined by Impatience to Spend Income and Opportunity to Invest It. Macmillan.

Jefferies. (2017). History and development of real estate investment (property) valuation models January

2017 https://www.researchgate.net/publication/316507454_History_and_development_of_real_estate_ investment_property_valuation_models/citations

Kelly, W., Epley, D. R., \& Mitchell, P. (1995). A requiem for Ellwood. The Appraisal Journal, 63(3), 284290.

KPMG. (2018). Property Lending Barometer: A survey of banks on the prospects for real estate sector lending in Europe, https://assets.kpmg/content/dam/kpmg/nl/pdf/2018/advisory/propertylending- barometer-2018.pdf.

Kucharska-Stasiak, E. (2019). Valuation Schools and the Evolution of the Income Approach. An Evaluation of Change Trends. Real Estate Management and Valuation, 27(2), 66-76. https://doi.org/10.2478/remav-2019-0016

Miller, M. H., \& Modigliani, F. (1961). Dividend policy, growth and the valuation of shares. The Journal of Business, 34, 411-433. https:// doi.org/10.1086/294442

Lombardo, R. (1998). Unravelling the mysteries of Ellwood's basic mortgage equity capitalisation model, Reseearch Gate Working Paper (October 1998) https://www.researchgate.net/publication/261983374_Unravelling_the_mysteries_of_Ellwood's_ basic_mortgage_equity_capitalisation_model

Metcalf, R. L. (2015). Understanding the roots of mortgage/equity capitalization. Journal of Property Tax Assessment $\mathcal{E}$ Administration, 23-31. https://researchexchange.iaao.org/jptaa/vol12/iss1/2

Michaletz, V., Artemenkov, A., \& Artemenkov, I. (2007) Income Approach and Discount Rates for Valuing Income-Producing Illiquid Assets - Outlines of New Framework: Revisiting the Concepts in Income Approach and Developing the Model of Illiquid Assets Transactional Pricing. ICFAI Journal of Applied Finance, December 2007; Proceedings of the ICFAI University and the University of Philadelphia V International Conference on Business and Finance, Hyderabad (India), 2006 Available at SSRN: https://ssrn.com/abstract=996016

Michaletz, V. B., \& Artemenkov, A. (2018). The Transactional Assets Pricing Approach and Income Capitalization Models in Professional Valuation: Towards a "Quick" Income Capitalization Format. Real Estate Management and Valuation, 26(1), 89-107. https://doi.org/10.2478/remav-2018$\underline{0008}$

Michaletz, V., \& Artemenkov, A. (2019). The transactional asset pricing approach: Its general framework and applications for property markets. Journal of Property Investment \& Finance, 37(3), 255-288. https:// doi.org/10.1108/JPIF-10-2018-0078

Mooya, M. (2016). Real estate valuation theory: A critical appraisal January 2016. University of Capetown, 2016. Advance online publication. https:// doi.org/10.1007/978-3-662-49164-5

Michael, S. (2018, Summer). Market value: What does it really mean? The Appraisal Journal, 206-235.

Sauder (2009). Course material: Mortgage-equity and Residual valuation techniques, Chapter 9 https://professional.sauder.ubc.ca/re_creditprogram/course_resources/courses/content/352/33 1_chapter09.pdf

RICS. (2017) 'The future of valuations: the relevance of real estate valuations for institutional investors and banks- views from a European expert group', Insight Paper of the Royal Institution of Chartered Surveyors, November [online] http://anavaliadores.pt/wp-content/uploads/2018/04/RICSFuture-of-Valuations-insights-paper.pdf

RICS. (2018) Bank lending valuations and mortgage lending value, 1st edition, RICS Professional Standards and Guidance (March 2018), https://www.rics.org/globalassets/ricswebsite/media/upholding-professional-standards/sector-standards/valuation/bank-lendingvaluations-and-mortgage-lending-value-1st-edition-rics.pdf 